\title{
Assessing the Emergent Public Health Concern of All-Terrain Vehicle Injuries in Rural and Agricultural Environments: Initial Review of Available National Datasets in the United States
}

Bryan Weichelt ${ }^{1}, \mathrm{PhD}, \mathrm{MBA}$; Serap Gorucu ${ }^{2}, \mathrm{PhD} ;$ Charles Jennissen $^{3}, \mathrm{MD} ;$ Gerene Denning ${ }^{3}$, PhD; Stephen Oesch ${ }^{4}$, JD

\footnotetext{
${ }^{1}$ National Farm Medicine Center, Marshfield Clinic Research Institute, Marshfield Clinic Health System, Marshfield, WI, United States

${ }^{2}$ Department of Agricultural and Biological Engineering, Penn State University, University Park, PA, United States

${ }^{3}$ Department of Emergency Medicine, University of Iowa Carver College of Medicine, Iowa City, IA, United States

${ }^{4}$ SLO, LLC, Bethesda, MD, United States
}

\section{Corresponding Author:}

Bryan Weichelt, PhD, MBA

National Farm Medicine Center

Marshfield Clinic Research Institute

Marshfield Clinic Health System

1000 N Oak Ave

Marshfield, WI, 54449

United States

Phone: 12217276

Email: weichelt.bryan@marshfieldresearch.org

\section{Abstract}

Background: Injuries related to the operation of off-road vehicles (ORVs), including all-terrain vehicles (ATVs), continue to be a significant public health concern, especially in rural and agricultural environments. In the United States alone, ATVs have played a role in thousands of fatalities and millions of injuries in the recent decades. However, no known centralized federal surveillance system consistently captures these data. Traditional injury data sources include surveys, police reports, trauma registries, emergency department data, newspaper and online media reports, and state and federal agency databases.

Objective: The objectives of this study paper were to (1) identify published articles on ORV-related injuries and deaths that used large databases and determine the types of datasets that were used, (2) examine and describe several national US-based surveillance systems that capture ORV-related injuries and fatalities, and (3) promote and provide support for the establishment of a federally-funded agricultural injury surveillance system.

Methods: In this study, we examined several national United States-based injury datasets, including the web-based AgInjuryNews, the Fatality Analysis Reporting System, databases compiled by the US Consumer Product Safety Commission, and the National Fatality Review Case Reporting System.

Results: Our review found that these data sources cannot provide a complete picture of the incidents or the circumstantial details needed to effectively inform ORV injury prevention efforts. This is particularly true with regard to ORV-related injuries in agricultural production.

Conclusions: We encourage the establishment of a federally funded national agricultural injury surveillance system. However, in lieu of this, use of multiple data sources will be necessary to provide a more complete picture of ORV- and other agriculture-related injuries and fatalities.

(JMIR Public Health Surveill 2020;6(2):e15477) doi: $10.2196 / 15477$

\section{KEYWORDS}

agriculture; all-terrain vehicle; fatality; injury; off-road vehicle; rural 


\section{Introduction}

\section{Background}

The group of vehicles generically referred to as off-road vehicles (ORVs) are gasoline- or diesel-powered motor vehicles designed to be used on a wide variety of off-road surfaces, including packed or loose dirt, rocks, sand dunes, snow, and marshlands. They typically have large low-pressure tires with knobby treads to grab off-road terrains. Vehicles equipped for use on sand dunes often have tires with paddle-like treads.

A popular ORV, which has been available since the 1970s, is the all-terrain vehicle (ATV; Figure 1). On ATVs, the rider straddles a motorcycle-like seat and uses handlebars to steer, brake, or accelerate. In many other countries, these vehicles are referred to as quads or quad bikes. ATVs have a narrow track width (distance between the middle of the right and left tires), a short wheelbase (distance between the axle or center point of the front and rear wheels), and a high center of gravity. Together, these result in low stability. Given their design, an ATV operator is required to use active riding, which involves the operator moving their pelvis and torso laterally and/or longitudinally on the seat, or vertically off the seat, while keeping both hands on the handlebars and both feet on the footrests throughout a maneuver, thus increasing the stability of the ATV and reducing the chance of a rollover [1].

Figure 1. All-terrain vehicle.

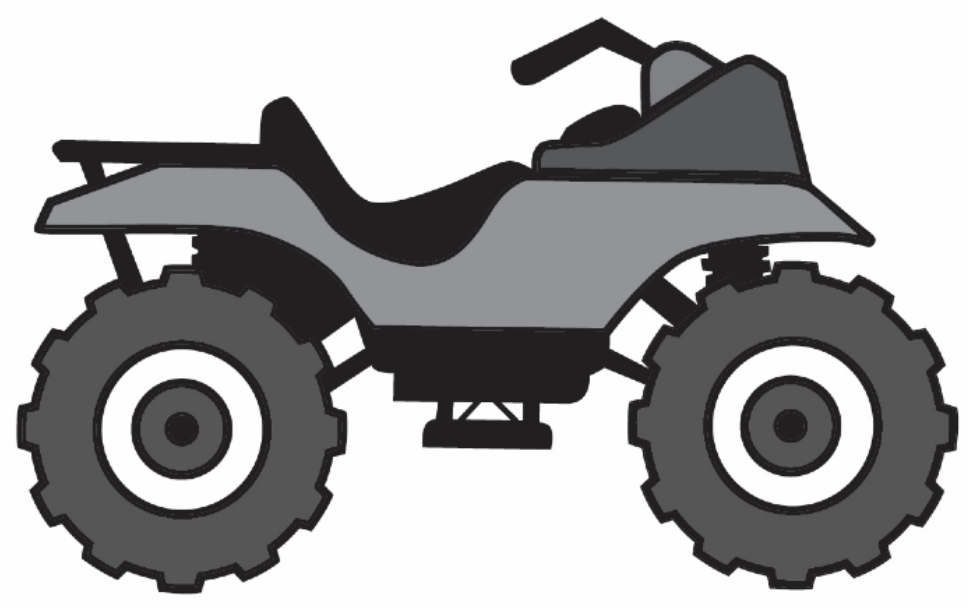

A second type of ORV that has gained increasing popularity over the past few decades is generically called a side-by-side $(\mathrm{S} \times \mathrm{S})$. This includes recreational off-highway vehicles (ROVs; Figure 2) and utility task/terrain vehicles (UTVs). ROVs and UTVs have automobile-like bench or bucket seats, a steering wheel, and foot pedals to activate the brake and accelerator. Some people refer to all $\mathrm{S} \times \mathrm{Ss}$ as UTVs, but, technically, light utility vehicles have maximum speeds of $25 \mathrm{mph}$, whereas all ROVs are capable of traveling greater than $30 \mathrm{mph}$ [2]. Owing to this, ROVs are required in the United States to have rollover protective structures (ROPS) and restraint devices such as seat belts or a harness system [3]. Although some UTVs have ROPS, many do not.

Figure 2. Recreational off-highway vehicle.

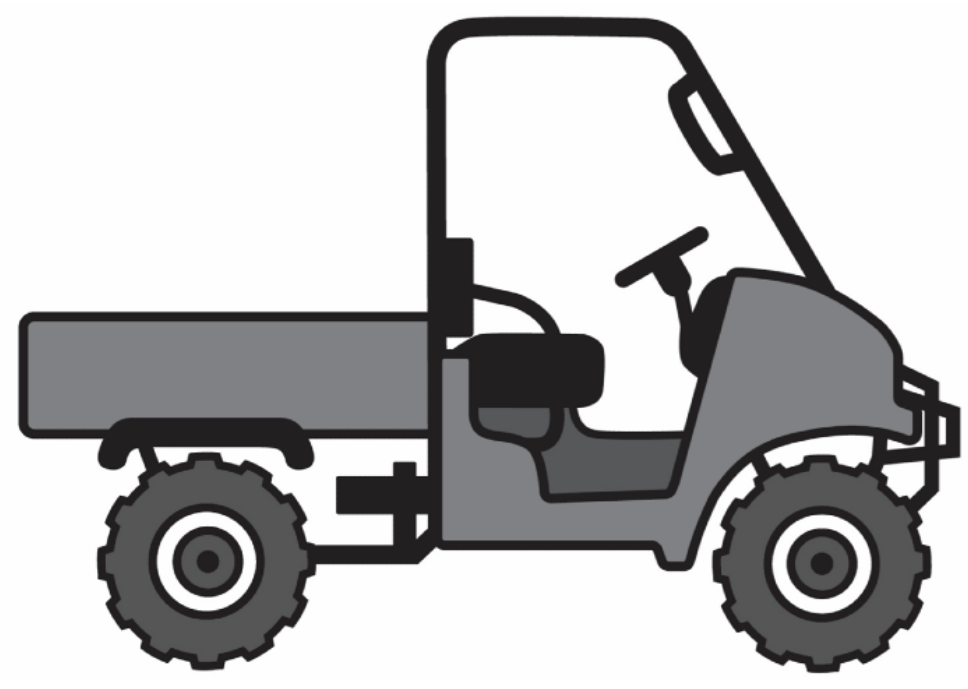




\section{Off-Road Vehicle Related Exposure and Injury}

Both ATVs and $\mathrm{S} \times \mathrm{Ss}$ are used for a wide range of recreational activities, such as trail and dune riding, hunting, and fishing, and occupational activities, such as forestry, farming, and ranching. In the spring of 2017, an estimated 10.5 million households owned an ATV (with many households owning more than one vehicle), and an additional 2.4 million reported that they intended to purchase an ATV within the next year [4]. This compares with an estimated 5.6 million ATVs in use in 2001 [5]. There is no similar publicly available data on the total number of $S \times S s$ in the United States. However, in its annual report filed with the US Securities and Exchange Commission, Polaris Industries estimated that during 2016, the worldwide sales of ATVs were approximately 400,000 vehicles and of ROVs were about 480,000 [6]. These data also show that the ORV market has been shifting from ATVs to ROVs in recent years.

Loss of control is a common risk resulting in traumatic injuries among ATV operators and passengers. Factors that increase the risk include younger age, being a male driver, inexperience, riding the wrong size ATV, carrying passengers, riding on the road, lack of helmets, and alcohol use [7]. ATVs have been implicated in 15,250 deaths between 1982 and 2017 in the United States [8]. During that period, $22 \%$ of the deaths were of children aged under 16 years, with $44 \%$ of those younger than 12 years [8]. Most of the deaths and injuries to youth (95\%) occur in adult-size vehicles, which they are neither supposed to operate nor ride as passengers [5,9-11]. In fact, more children aged under 16 years in the United States die from ATVs than from bicycle crashes [12], and they have 12 times higher risk of injury than older adults [13]. Furthermore, the economic costs of morbidity and mortality from ATV crashes are high [12].

\section{Public Roadways}

Despite ORVs being designed for off-road use only and manufacturers warning that the vehicles should not be used on public roads, most ATV fatalities occur on roadways $[7,14,15]$. Between 2004 and 2013, the National Highway Traffic Safety Administration (NHTSA) reported that ATV-related fatalities in their Fatality Analysis Reporting System (FARS) ranged from a low of 307 in 2012 to a high of 381 in 2008. Data from 2017 showed that $87 \%$ of ATV-related roadway deaths were of drivers [16]. Helmet use was low, with only $9 \%$ wearing helmets. Most of the deaths occurred in single-vehicle crashes $(71 \%)$ and in rural areas $(79 \%)$. In addition, $40 \%$ of fatally injured ATV operators had a blood alcohol level (BAC) of 0.08 or higher, compared with $28 \%$ of motorcycle operators [16].

Surprisingly, despite the trends of injury and death associated with ORVs on public roadways, many municipalities and counties have already enacted or are considering ordinances that would allow open access to ORVs on their roads [17]. Elected officials and law enforcement personnel are often contacted by concerned citizens, health care providers, and injury prevention experts who oppose such legislation. However, more often than not, evidence-based arguments, peer-reviewed literature, testimonials, and media reports have had little to no effect. According to the Consumer Federation of America
(CFA), a nonprofit research and education organization, there is a national trend that is gaining greater traction to enact local and state laws to allow ORVs on public roads, with no decline in the foreseeable future [17]. From April 2014 to September 2018, the CFA sent more than 180 letters opposing the use of ORVs on public roads to state and local officials in 27 states, with 40 in the state of Wisconsin alone [18].

\section{Off-Road Vehicles in Agriculture}

Farmers and ranchers were early purchasers and have described ATVs as filling a valuable niche between a truck and a tractor [19]. These versatile machines are leveraged for a variety of agricultural work-related tasks [20]. These include inspecting crops and livestock, tilling, herding animals, spraying pesticides and herbicides, plowing or blowing snow, towing or hauling farm supplies and products, and other general transportation and labor tasks. It is expected that the prevalence of ORV use in farming and ranching, both occupational and recreational, will continue to increase [21].

The incidence of fatal and nonfatal injuries in the Agriculture, Forestry and Fishing industrial sector has become difficult to quantify, particularly after the National Institute for Occupational Safety and Health (NIOSH) discontinued national surveys of nonfatal injuries to self-employed farmers, ranchers, and children on farms. However, the Occupational Safety and Health Administration (OSHA) reported that from 2003 to 2013, there were 2090 injuries and 321 deaths because of occupational use of ATVs, with $60 \%$ of ATV-related fatalities occurring in agriculture [22]. The use of ATV-mounted weed sprayer tanks is especially problematic as mounting the tank on the vehicle both raises and shifts the center of gravity, making an already unstable vehicle even more likely to overturn [23].

\section{Objective}

The objectives of this study were to (1) identify published articles on ORV-related injuries and deaths that used large databases and determine the types of datasets that were used, (2) examine and describe several national United States-based surveillance systems that capture ORV-related injuries and fatalities, and (3) promote and provide support for the establishment of a federally funded agricultural injury surveillance system.

\section{Methods}

\section{Review of Injury Data Sources}

An electronic literature search of all articles published between 2014 and 2018 was conducted using PubMed to identify ORV-related articles. The terms used in various combinations in Medical Subject Headings and keyword searches included "off-road vehicles," "fatalities," "accidents," "wounds," "injuries," "ATV," "UTV," and "mortality." Our search yielded 70 results, and the abstracts of these articles were reviewed. Published reports were included in this study if they had used a large database of stored information from which they identified ORV-related crashes, injuries, or deaths. A total of 17 articles met the inclusion criteria. 


\section{National Datasets}

In this report, 4 national United States-based datasets that include ORV-related crashes and injuries were selected for review: AgInjuryNews, Consumer Product Safety Commission (CPSC), FARS, and the National Fatality Review Case Reporting System (CRS). Although this paper focuses on 4 US databases, there are several other national datasets that include ORV-related injuries and/or deaths. For example, the Bureau of Labor Statistics (BLS) collects the US occupational injury and fatality data. Under the auspices of the BLS, the Census of Fatal Occupational Injuries captures occupational fatalities, including those of volunteers and undocumented workers [24], and the Survey of Occupational Injury and Illnesses database collects nonfatal occupational injuries, including those solicited from agricultural employers having more than 10 employees [24]. The OSHA also investigates work-related fatalities, but excludes self-employed individuals, members of the immediate family of farm employers, and employees of state and local governments. In addition, the OSHA investigation's inclusion/exclusion and general oversight criteria vary from state to state [25]. Neither BLS nor OSHA captured bystander or passenger injuries, unless the bystander or passenger was also working at the time of the incident. In summary, BLS and OSHA data provide a very limited view of agricultural injuries, and for these reasons, they were not included or further explained in this review.

\section{Ethics Approval and Informed Consent}

No human subjects were involved in this project.

\section{Results}

\section{Systematic Review}

Table 1 summarizes the 17 ORV-related articles published between 2014 and 2018 that used large datasets. Most researchers have used trauma center and/or emergency department (ED) data as well as data from the FARS; the CPSC, including their National Electronic Injury Surveillance System (NEISS); and state departments of transportation (DOTs). These studies primarily focused on demographics, severity of injury, body part injured, and risk factors. However, sources that included a variety of vehicle- and crash-related variables rarely indicated whether the vehicle was used for recreational or occupational purposes [26].

Table 1. Summary of off-road vehicle-related studies (2014-2018) and the data sources used.

\begin{tabular}{|c|c|c|c|}
\hline Reference (year) & Data source & Study period & Study populations \\
\hline Richardson et al (2018) [27] & FARS $^{\mathrm{a}}, \mathrm{CPSC}^{\mathrm{b}}$, and vehicle sales database & $2000-2015$ & All age groups \\
\hline Nabaweesi et al (2018) [28] & National Emergency Department Sample & $2006-2011$ & Pediatric (0-17 years) \\
\hline Karkenny et al (2018) [29] & NEISS $^{\mathrm{c}}$ & $1991-2014$ & $2-18$ years \\
\hline Testerman et al (2018) [30] & Level I trauma center & $2005-2015$ & All age groups \\
\hline Nolan et al (2018) [31] & Level I trauma center & $1999-2005$ & All age groups \\
\hline Flaherty et al (2017) [32] & Massachusetts emergency departments & $2002-2013$ & Pediatric (0-17 years) \\
\hline Benham et al (2017) [33] & Level I trauma center & $2008-2012$ & Adult and pediatric \\
\hline Lombardo et al (2017) [34] & NEISS & $2007-2012$ & Pediatric (0-17 years) \\
\hline Garay et al (2017) [35] & Pennsylvania State Trauma Database & 2004-2014 & Pediatric ( $0-17$ years) \\
\hline Qin et al (2017) [36] & $\begin{array}{l}\text { Iowa Department of Transportation, Department of Natural Resources, and } \\
\text { State Trauma Registry }\end{array}$ & $2002-2013$ & All age groups \\
\hline Gorucu et al (2017) [37] & Pennsylvania Department of Transportation roadway crash data & $2010-2013$ & All age groups \\
\hline Linnaus et al (2016) [38] & Level 1 pediatric trauma center & $2007-2015$ & Pediatric ( $0-17$ years) \\
\hline Bethea et al (2016) [39] & Level 1 trauma center & 2005-2013 & All age groups \\
\hline Lagerstorm et al (2016) [40] & CPSC & 2011-2013 & All age groups \\
\hline Sciarretta et al (2016) [41] & Level II trauma center & Not available & Pediatric ( $0-17$ years) \\
\hline Williams et al (2014) [42] & FARS & $2007-2011$ & All age groups \\
\hline Denning et al (2014) [9] & CPSC & $1985-2009$ & Pediatric ( $0-17$ years $)$ \\
\hline
\end{tabular}

${ }^{a}$ FARS: Fatality Analysis Reporting System.

${ }^{\mathrm{b}}$ CPSC: Consumer Product Safety Commission.

${ }^{\mathrm{c}}$ NEISS: National Electronic Injury Surveillance System.

\section{National Datasets for Off-Road Vehicle-Related Injuries and Deaths}

Similar to many other subsectors of injury prevention and injury epidemiology, there is a lack of a comprehensive national injury surveillance system for ORV-related injuries, including those from agricultural use of the vehicle. In the following sections, descriptions of the 4 selected national datasets are provided. Table 2 summarizes the characteristics of these national data sources for ORV-related injuries and deaths. 
Table 2. Characteristics of national data sources for all-terrain vehicle-related injuries.

\begin{tabular}{|c|c|c|c|c|}
\hline Properties & AgInjuryNews & $\mathrm{CPSC}^{\mathrm{a}}$ & $\begin{array}{l}\text { Fatality Analysis Reporting } \\
\text { System }\end{array}$ & $\begin{array}{l}\text { The National Fatality Review } \\
\text { CRS }^{\text {b }}\end{array}$ \\
\hline Responsible organization & $\begin{array}{l}\text { National Farm Medicine } \\
\text { Center and Marshfield } \\
\text { Clinic Research Institute }\end{array}$ & $\begin{array}{l}\text { Independent agency of US } \\
\text { government }\end{array}$ & $\begin{array}{l}\text { National Highway Traffic } \\
\text { Safety Administration }\end{array}$ & $\begin{array}{l}\text { National Center for Fatality } \\
\text { Review and Prevention }\end{array}$ \\
\hline Purpose & $\begin{array}{l}\text { To provide an interactive } \\
\text { display of publicly avail- } \\
\text { able injury reports data } \\
\text { involving } \mathrm{AgFF}^{\mathrm{c}} \text {-related } \\
\text { injuries and fatalities }\end{array}$ & $\begin{array}{l}\text { To protect the public against } \\
\text { unreasonable risks of injury } \\
\text { or death from consumer prod- } \\
\text { ucts through education, safety } \\
\text { standards activities, regula- } \\
\text { tion, and enforcement }\end{array}$ & $\begin{array}{l}\text { To provide an overall measure } \\
\text { of highway safety, to help } \\
\text { suggest solutions, and to help } \\
\text { provide an objective basis to } \\
\text { evaluate the effectiveness of } \\
\text { motor vehicle safety standards } \\
\text { and highway safety programs }\end{array}$ & $\begin{array}{l}\text { To promote, support, and en- } \\
\text { hance fatality review method- } \\
\text { ology and activities for fetal } \\
\text { and infant mortality review } \\
\text { and CDR }\end{array}$ \\
\hline $\begin{array}{l}\text { Inclusion and exclusion } \\
\text { criteria }\end{array}$ & $\begin{array}{l}\text { Included: injuries and fa- } \\
\text { talities related to AgFF; } \\
\text { excluded: recreational } \\
\text { and non-AgFF cases }\end{array}$ & $\begin{array}{l}\text { Included: consumer prod- } \\
\text { uct-related injuries evaluated } \\
\text { at NEISS }{ }^{\mathrm{e}} \text { emergency depart- } \\
\text { ments and consumer prod- } \\
\text { uct-related fatalities; exclud- } \\
\text { ed: CPSC notes that some } \\
\text { states may not report all all- } \\
\text { terrain vehicle deaths within } \\
\text { their state }\end{array}$ & $\begin{array}{l}\text { Included: fatal traffic crashes } \\
\text { involving a motor vehicle on } \\
\text { public roadways; excluded: } \\
\text { motor vehicle deaths occur- } \\
\text { ring > } 30 \text { days after the inci- } \\
\text { dent }\end{array}$ & $\begin{array}{l}\text { Included: all child deaths re- } \\
\text { viewed by local review teams } \\
\text { in states that utilize the CDR } \\
\text { CRS }\end{array}$ \\
\hline Data collection period & 2015 to present & 1982 to present & 1975 to present & 2005 to present \\
\hline Primary data sources & $\begin{array}{l}\text { News media, social me- } \\
\text { dia, obituaries, police re- } \\
\text { ports, and Fatality Assess- } \\
\text { ment and Control Evalua- } \\
\text { tion reports }\end{array}$ & $\begin{array}{l}\text { NEISS, death certificates, in- } \\
\text { depth CPSC investigations, } \\
\text { news media, and coroner/med- } \\
\text { ical examiner reports }\end{array}$ & $\begin{array}{l}\text { Police crash reports, death } \\
\text { certificates, state vehicle reg- } \\
\text { istration files, coroner/medi- } \\
\text { cal examiner reports, state } \\
\text { driver licensing files, hospital } \\
\text { medical reports, state highway } \\
\text { department data, emergency } \\
\text { medical service reports, vital } \\
\text { statistics, and other state } \\
\text { records }\end{array}$ & $\begin{array}{l}\text { Agencies represented on CDR } \\
\text { teams share case-specific in- } \\
\text { formation at multidisciplinary } \\
\text { meetings. Represented agen- } \\
\text { cies include, but are not limit- } \\
\text { ed to, medical examiner or } \\
\text { coroner, law enforcement, } \\
\text { child protective services, } \\
\text { medical providers, and school } \\
\text { districts }\end{array}$ \\
\hline Data collection methods & $\begin{array}{l}\text { News media monitoring } \\
\text { service, Google Alerts, } \\
\text { and submissions from } \\
\text { colleagues and users }\end{array}$ & $\begin{array}{l}\text { Death certificates, news me- } \\
\text { dia monitoring, and CPSC } \\
\text { crash investigations }\end{array}$ & $\begin{array}{l}\text { State submission of police } \\
\text { crash reports and other data }\end{array}$ & $\begin{array}{l}\text { Cases are identified through } \\
\text { medical examiners, coroners, } \\
\text { and vital records }\end{array}$ \\
\hline $\begin{array}{l}\text { Crash location-related } \\
\text { variables }\end{array}$ & Location and type of road & Location and type of road & $\begin{array}{l}\text { Location, type of road, crash } \\
\text { characteristics, environmental } \\
\text { conditions, and first harmful } \\
\text { event }\end{array}$ & $\begin{array}{l}\text { Location and driving condi- } \\
\text { tions }\end{array}$ \\
\hline Vehicle-related variables & Vehicle type & $\begin{array}{l}\text { Engine size; vehicle type, } \\
\text { make, and model; and the } \\
\text { presence of passengers }\end{array}$ & $\begin{array}{l}\text { Vehicle type, make, and } \\
\text { model; most harmful event; } \\
\text { extent of damage; and vehi- } \\
\text { cle- and driver-level related } \\
\text { factors }\end{array}$ & $\begin{array}{l}\text { Child's vehicle, other primary } \\
\text { vehicle, and number of occu- } \\
\text { pants }\end{array}$ \\
\hline Victim-related variables & $\begin{array}{l}\text { Demographics, opera- } \\
\text { tor/passenger, injury } \\
\text { severity (fatal/nonfatal), } \\
\text { agricultural work related- } \\
\text { ness, safety equipment } \\
\text { (eg, helmet, seatbelt, and } \\
\text { gear), injury event, and } \\
\text { injury sources }\end{array}$ & $\begin{array}{l}\text { Demographics, vehicle safety } \\
\text { training, operators' } \\
\text { height/weight, and alco- } \\
\text { hol/drug usage }\end{array}$ & $\begin{array}{l}\text { Demographics, seating posi- } \\
\text { tion, alcohol/drug usage and } \\
\text { test results, fatal injury at } \\
\text { work, and safety equipment } \\
\text { (eg, helmet, seatbelt, and } \\
\text { gear) }\end{array}$ & $\begin{array}{l}\text { Demographics, seating posi- } \\
\text { tion, causes of incident (eg, } \\
\text { speeding and distraction), ve- } \\
\text { hicle safety training, safety } \\
\text { equipment (eg, helmet, seat- } \\
\text { belt, and gear), and alco- } \\
\text { hol/drug usage }\end{array}$ \\
\hline
\end{tabular}

${ }^{\mathrm{a} C P S C}$ : Consumer Product Safety Commission.

${ }^{\mathrm{b}} \mathrm{CRS}$ : Case Reporting System.

${ }^{\mathrm{c}} \mathrm{AgFF}$ : agriculture, fishing, and forestry.

${ }^{\mathrm{d}} \mathrm{CDR}$ : child death review.

eNEISS: National Electronic Injury Surveillance System. 


\section{AgInjuryNews}

AgInjuryNews was developed by the National Farm Medicine Center and launched in 2015 [24]. The team responsible for this endeavor compiles AgFF-related injuries and fatalities from publicly available sources such as news media outlets, obituaries, social media, and police reports [24]. This is accomplished through several search platforms, including a media monitoring service, Google Alerts, social media (eg, sheriff departments' Facebook pages and GoFundMe), and submissions from colleagues [24]. Data are collected, coded, uploaded to the center's interactive searchable website, and made available for public use. The goal of this repository is to provide a comprehensive list of all deaths and injuries occurring on farms and ranches, including cases involving children as bystanders and/or farm visitors [20]. Data collection methods of the AgInjuryNews initiative are further described in a different paper [43]. Data for this study were available to the authors of this paper through prearranged administrative privileges.

ORV-related injuries occurring on a farm or ranch are included in the AgInjuryNews database. To distinguish occupational ORV-related fatalities, AgInjuryNews researchers use farm and agricultural injury classification (FAIC) codes. FAIC codes provide a systematic scheme for separating farm/agricultural production work cases [44]. It is often difficult to differentiate between occupational and nonoccupational ORV-related cases as there might not be enough detailed information from news reports to use the FAIC. AgInjuryNews researchers often follow-up and try to gather more information to distinguish occupational from nonoccupational cases.

With regard to ORV-related cases, AgInjuryNews uses the Occupational Injury and Illness Classification System (OIICS) for coding the vehicle involved in the injury. There is a specific OIICS code for ATVs (code: 8611), but not for other types of ORVs. AgInjuryNews coders use the OIICS code 8619 (off-road passenger vehicles-powered, not elsewhere classified) for ORVs other than ATVs [45]. Other variables available in the database include demographics of injured victims, crash location (eg, roadway, farm, field, or orchard), whether the incident was work-related or recreational, injury source (eg, vehicle type), event/activity at the time of the incident (transportation, fall, or contact), and others. Detailed information on the available variables can be found in AgInjuryNews [46].

In the past, a collection of news reports could successfully capture nearly all fatal incidents and identify agricultural injury and fatality cases at the local, regional, and national levels [47,48]. The AgInjuryNews initiative has become a systematic, up-to-date, web-based collection of agriculture-related injuries and fatalities that fill a surveillance gap and provide national-level data to guide research, injury prevention efforts, and organizational policy for agribusiness [24]. Media reports collected by AgInjuryNews over time have shown how the ATV-related injury category has quickly risen to the top as a source of injury among youth in agriculture, with ATVs being the second leading cause of nonfatal injuries and the leading cause of fatal injuries among those younger than 18 years [24].

The AgInjuryNews dataset, established in 2015, is limited by the information available in the original sources, which are primarily web-based news media reports [43]. These types of reports likely capture more serious traumatic injuries and fatalities. However, media reports are inherently inconsistent in the type of information they provide. For example, not every journalist asks the same questions, or they may simply redistribute statements from the responding sheriff's department or fire chief. When the injury is nonfatal, data variables such as age and gender are not always reported. Moreover, journalists often mislabel the various types of ORVs involved, for example, calling an $\mathrm{S} \times \mathrm{S}$ an ATV. Sometimes this error can be identified by other information included in the article, such as the rider not using their seat belt (only available on $\mathrm{S} \times \mathrm{Ss}$ ), but not always. To further complicate things, DOT data also vary across states, based on how ATVs and $\mathrm{S} \times \mathrm{Ss}$ are coded. In addition, this dataset may inadvertently include cases that are not agricultural because of the difficulty in identifying vehicle use at the time of the crash.

\section{Consumer Product Safety Commission}

As ORVs are designed for off-road use only, manufacturers are not regulated by the Federal Motor Vehicle Safety Standards issued by NHTSA for roadway vehicles. Instead, they are regulated by the CPSC, an independent 5-member commission. The CPSC releases an annual report on the deaths and injuries related to ATV use in the United States. There are no comparable annual reports on the deaths and injuries related to $\mathrm{S} \times \mathrm{Ss}$. On the basis of the cases collected by the CPSC, estimated deaths from the use of ATVs peaked at 923 in 2005 and declined to 651 in 2013. However, the number of fatalities appears to be increasing again, as there were an estimated 708 deaths in 2015 [8].

Data collected by the CPSC on ATV-related fatalities are available to researchers upon request for secondary analyses. This is accomplished by completing and submitting a Freedom of Information Act request form through the CPSC website [49]. The CPSC also prepares estimates of hospital ED-treated injuries related to consumer products through its NEISS, which is a probability sample of EDs in the United States. There were an estimated 93,800 ATV-related injuries treated in EDs in 2017. Of those injuries, the CPSC estimates that 24,800 (26\%) were to children under 16 years [8].

Public access to the NEISS is available through the CPSC website, and individuals may view and download the national injury estimates for a multitude of consumer products, including ATVs [50]. NEISS uses 4 different codes for ATVs based on the number of wheels $(3,4$, more than 4 , and unspecified number of wheels). Through the NEISS Query Builder, customized searches may be performed, and deidentified case data may be downloaded for further analysis. Variables available include demographics (age, sex, and race), product involved, date of injury, general location where the injury occurred, body part injured, diagnosis, and patient disposition. There is also a brief narrative that provides a description of the incident.

The CPSC fatality data are limited with regard to information about crash events and driver actions [42]. Some variables such as information on the make and model of the ATV involved in 
the crash are restricted and not made available to the public [47]. A major limitation of the CPSC data is that there is a substantial time lag in reporting data on ATV fatalities. For example, the most recent annual report was released in February 2019, but the last year for which ATV fatality data in this report were considered complete was 2014. Data collection was still ongoing at the time of this study for 2015 to 2017 [8].

Although the CPSC began its collection of ATV fatality data in 1982, the agency switched from using death certificate mortality codes under the ninth revision of the International Classification of Diseases to the tenth revision in 1999. The CPSC says that comparisons of pre-1999 data with the later data "should be undertaken with caution" [51]. In addition, CPSC death counts by state reflect the state in which the death occurred rather than the state in which the crash occurred. Using emergency medical services' air and ground transportation for the most critically injured ATV riders to level 1 trauma centers in other states may inflate the number of deaths reported for a state in which the rider was finally treated. Unfortunately, the CPSC does not actively collect data related to $\mathrm{S} \times \mathrm{Ss}$ and does not include them in their annual ATV death and injury reports.

The NEISS is an easily accessible database that provides probability sampling of national ED data, but it is fairly limited in the information it collects. The mechanism of the crash and injury is not coded, and information regarding key risk factors for ATV crashes and injuries such as helmet use, presence of passengers, vehicle engine size, alcohol and other drug use, and vehicle speed are also not specifically recorded. The short narrative often provides some of this information, but it is not reliably documented. Although the NEISS does have a code for utility vehicle, there are no further categorizations in the system for this type of vehicle, and vehicles other than UTVs and ROVs may be coded under this designation.

\section{Fatality Analysis Reporting System}

NHTSA maintains the FARS, which is a census of and the sole source of all police-reported motor vehicle-related fatalities on public roads in the United States [52]. This data collection system, which was established in 1975, includes both motorists and nonmotorists who die within 30 days of being involved in a motor vehicle traffic crash [53]. Through a cooperative agreement with agencies in each state, NHTSA collects fatality crash data that are converted to the SAS data format. The sources of the FARS data include, among other things, police crash reports, death certificates, and coroner/medical examiner reports [53]. FARS cases are only considered to be work-related if the injury at work response item on the death certificate is checked [54].

The FARS query system allows public access to the database. Data may be processed utilizing the site's interactive user interface, and customized searches may be performed. A create-a-map feature allows individuals to build county-by-county and state-by-state maps displaying personally selected results from the FARS data. Published files may also be downloaded from the FARS website (ftp://ftp.nhtsa.dot.gov/FARS) as compressed delimited text files or SAS data files. Requests for specific data may be made to the NHTSA National Center for Statistics and Analysis at no charge, and it usually takes about 2 weeks depending on the complexity of the data requested.

The FARS data contain more than 100 separately coded elements [53]. In addition to demographic information, the dataset includes a number of variables noted to be risk factors for ATV crash and injury, including helmet use, seating position, presence of passengers, speed, and BAC. The roadway type and type of surface, specific location of the crash on the road, and rural/urban location data are also available. FARS provides a number of variables that distinguish what happened in the crash, including the number and type of vehicles involved; the first harmful event that occurred; the crash configuration and maneuvering of each vehicle involved; and driver-related contributing factors for every vehicle, based on police judgment.

In 2013, the Insurance Institute for Highway Safety, a nonprofit research and communications organization funded by motor vehicle insurers, released the first study to use FARS data to identify the characteristics of on-road fatal ATV crashes [42]. A primary reason for conducting the study was that CPSC data showed that most ATV deaths occurred on public roadways rather than off road [14,15].

The FARS dataset is limited to police-reported fatalities on public roadways and does not include those occurring off road. Moreover, FARS uses body type code 90 for ATVs with 3 or 4 wheels, but $\mathrm{S} \times \mathrm{Ss}$, including ROVs and UTVs, have also been coded under this body type as well as in the other vehicle category. Although one could try to use vehicle identification numbers (VINs) to delineate these ORV types, only about one-half of VINs could be decoded in an ATV study utilizing FARS data [42]. Beginning with its report on 2017 fatalities, NHTSA added a new category, recreational off-highway vehicles, to cover ROVs [55,56]. Therefore, this database may be more useful to conduct studies related to ROVs on public roadways in the future. In addition, FARS inclusion requires the person's death to be within 30 days of the crash, and fatalities occurring beyond this period would be missed.

\section{The National Fatality Review Case Reporting System}

The National Center for Fatality Review and Prevention (NCFRP) is funded by the Maternal and Child Health Bureau under the Health Resources and Services Administration and is the national resource and data center for fetal and infant mortality review and child death review (CDR) [57]. The NCFRP manages and promotes the use of the National Fatality Review CRS, which is a standardized case report tool made available to all states. Currently, 43 states utilize CRS with over 2100 data users [57].

The National Fatality Review CRS contains more than 2600 variables that describe in detail the risk factors and circumstances surrounding a child's death. Although each state varies in its data collection process, information for the case report is generally gathered through multidisciplinary team meetings. The case report is deidentified at the national level. Many states will disseminate their CDR findings into reports to educate policy makers and the general public about the key risk factors and opportunities for injury prevention. Researchers may apply to utilize the national dataset for injury prevention 
studies [58]. NCFRP's policies and guidelines should be followed by researchers to apply and use their data.

The dataset only includes deaths reviewed by CDR teams, not all child deaths; therefore, it cannot be used to calculate incidence. In addition, case reports are completed by numerous data users, which can lead to variability in data completeness.

\section{Discussion}

\section{Principal Findings}

A plethora of published research shows that ATV-related deaths and injuries are a significant and ongoing public health concern, including in rural areas and among youth. Although few studies of $\mathrm{S} \times \mathrm{S}$-related crashes are available, data suggest that injuries and deaths associated with them are an emerging public health issue. Ongoing research is critically needed, including research on agricultural ORV injury prevention.

One of the greatest challenges to ORV-related research is the lack of a single comprehensive data source for fatalities and injuries. This review of some national databases providing information on ORV-related deaths and injuries demonstrates that each database has significant limitations, especially regarding the ability to distinguish recreational from occupational crashes.

Although AgInjuryNews provides agricultural work-related information, it is unable to provide a comprehensive picture of all ORV-related crashes on farms and ranches, as not all rural injuries will be covered by media. Despite this, state and regional efforts to collect media related to agricultural injuries and deaths have grown in number. There are no federally supported comprehensive national databases on agricultural work-related deaths and injuries; such efforts provide some insight into work-related injuries and emerging issues to those involved in agricultural injury prevention. As AgInjuryNews collects data nationally and makes it available to the public, it may supersede more localized efforts and become increasingly more important as a supplemental surveillance system to study agricultural work-related injuries and deaths, including those because of ORVs.

The CPSC ATV fatality database provides information on most, but not all, ATV-related fatalities in the nation. Although it codes whether the activity at the time of the crash was work-related, there is little additional information, and it is not possible to determine if it occurred while agricultural work was being performed.

The NEISS database, also maintained by the CPSC, does not specify whether the injury was work-related, limiting its utility for the study of agricultural work-related ATV injuries. As a part of its proposed rulemaking in 2009, designed to create an improved safety standard for ROVs, CPSC released studies on $\mathrm{S} \times \mathrm{S}$-related fatalities and injuries [3]. However, CPSC has not updated that information to cover more recent years, and the CPSC does not publish an annual report on ROV-related deaths and injuries, similar to what they do for ATVs.

The FARS database provides a great deal of information regarding ORV-related roadway fatalities; however, ORVs are designed to be used off road, and there are a substantial number of fatalities that are not included. In addition, FARS identifies work-related fatalities using only the injury at work item on the death certificate, and it does not indicate what type of work activities were being performed at the time of the incident. Thus, identifying agricultural work-related fatalities is not possible using FARS data. As noted previously, with the new code of ROV added in 2017, FARS data could be used to study ROV roadway crashes in the future.

National Fatality Review CRS data comprise many details regarding the mechanisms and activities that were being performed at the time of the fatal crash. This includes the vehicles involved in the incident, including ORVs, and information regarding whether work was being performed. Unfortunately, not all child deaths fall under the auspices of a state or county CDR team. Thus, the CRS data may be rich in detail but may not provide accurate total counts of ORV-related deaths. Moreover, not all states participate in the system. These identified gaps not only hinder the lines of inquiry but also highlight important future work for the discipline.

Although there are challenges in law enforcement, the passage of laws (such as those requiring helmet use while riding ORVs and seat belt use while riding in ROVs) is another important method to reduce the frequency and severity of injuries when ORVs crash [59-64]. Moreover, crash and injury prevention measures found to be effective should be replicated across the country. Given the prevalence of ORV-related injuries and deaths, solutions beyond traditional approaches to improve the health and safety of rural ORV operators need to be found and disseminated.

There is also an upward trend of municipalities permitting the use of ORVs on paved and unpaved public roads to appease constituents, power sport dealerships, and ORV clubs. Active efforts by individuals and community groups are greatly needed to affect decision making and ordinances at the local level [65]. Safety and health professionals and associated organizations should advocate for policy change at the state and national levels, and policy makers need to be made more aware of the issue, encouraged to pass evidence-based safety laws, and discouraged from passing laws that decrease safety, such as opening public roadways to recreational use of ORVs $[14,15,42]$. Such efforts need to be considered a priority by injury prevention stakeholders, including legislators, to address this growing public health concern.

\section{Conclusions}

Deficiencies in national agricultural injury surveillance efforts continue to plague subsectors of injury prevention research and practice, including efforts to reduce ORV-related injuries. Our review provides illustrations of how the currently available datasets used to perform agricultural ORV-related injury surveillance, and in fact, all agricultural injury surveillance, are inadequate. Significant limitations exist for both individual data sources and even, where possible, merged data from multiple sources. These limitations provide a strong rationale for a robust national surveillance system for agricultural deaths and injuries, which could facilitate the development and evaluation of injury prevention approaches, including evidence-based safety 
engineering and legislation. A discussion of what such a surveillance system should look like and how it should operate is highly complex and, thus, beyond the scope of this review.
However, robust injury surveillance is an essential element in successful efforts to save lives, protect health, and reduce the high costs of preventable injuries.

\section{Acknowledgments}

The authors thank Amy Parry, Data Project Manager at the Children's Health Alliance of Wisconsin, and Heather Dykstra, Senior Data Analyst at the NCFRP, for their input and guidance regarding the summary and details of the NCFRP dataset. The authors also thank Emily Redmond of the National Farm Medicine Center for assistance with data and definitions regarding the AgInjuryNews system. The authors also thank Debra Knipple, Medical Library Reference Librarian at the Marshfield Clinic Heath System, for her assistance with the literature review. Finally, the authors would also like to thank Marie Fleisner for her assistance with editing the manuscript and Jenna Kautza from Marshfield Clinic Information Systems for her design work of the 2 figures in this paper. Funding support was provided through the National Farm Medicine Center, the Marshfield Clinic Research Institute, the Dean Emanuel Endowment, and the National Children's Center for Rural and Agricultural Health and Safety via CDC/NIOSH (grant number U54 OH009568). Funding was also provided by the Central States Center for Agricultural Safety and Health via CDC/NIOSH (grant number U54 OH 010162-07).

\section{Authors' Contributions}

All authors participated in the conception or design of the work; the acquisition, analysis, or interpretation of data for the work; drafting the work and revising it critically for important intellectual content; and final approval of the version to be submitted/published; and all authors agree to be accountable for all aspects of the work in ensuring that questions related to the accuracy or integrity of any part of the work are appropriately investigated and resolved.

\section{Conflicts of Interest}

None declared.

\section{References}

1. Lock J. Queensland Courts. Brisbane, Queensland, Australia: Office of the State Coroner; 2015 Aug 3. Inquest Into Nine (9) Deaths Caused by Quad Bike Accidents URL: https://www.courts.qld.gov.au/ data/assets/pdf file/0018/432306/ cif-quadbikeaccidents-20150803.pdf [accessed 2019-09-14]

2. Federal Register. 2014. Safety Standard for Recreational Off-Highway Vehicles (ROVs): A Proposed Rule by the Consumer Product Safety Commission URL: https://www.federalregister.gov/documents/2014/11/19/2014-26500/ safety-standard-for-recreational-off-highway-vehicles-rovs [accessed 2020-04-01]

3. Consumer Product Safety Commission. Federal Register. 2014 Nov 19. Safety Standard for Recreational Off-Highway Vehicles (ROVs) URL: https://www.federalregister.gov/documents/2014/11/19/2014-26500/ safety-standard-for-recreational-off-highway-vehicles-rovs [accessed 2019-02-13]

4. Statista. 2018. Share of Americans Who Own an ATV (All-Terrain Vehicle) in 2018, by Age URL: https://www.statista.com/ statistics/228874/people-living-in-households-that-own-an-atv-all-terrain-vehicle-usa/ [accessed 2019-02-13]

5. Levenson MS. Consumer Product Safety Commission. 2003 Jan. All-Terrain Vehicle 2001 Injury and Exposure Studies URL: https://www.cpsc.gov/s3fs-public/pdfs/atvex2001.pdf [accessed 2019-02-13]

6. Annual Reports. 2016. Polaris Industries URL: http://www.annualreports.com/HostedData/AnnualReportArchive/p/ NYSE PII 2016.pdf [accessed 2019-02-13]

7. Denning GM, Jennissen CA. All-terrain vehicle fatalities on paved roads, unpaved roads, and off-road: Evidence for informed roadway safety warnings and legislation. Traffic Inj Prev 2016 May 18;17(4):406-412. [doi: 10.1080/15389588.2015.1057280] [Medline: 26065484]

8. Topping J. Consumer Product Safety Commission. 2019 Feb. 2017 Annual Report of ATV-Related Deaths and Injuries URL: https://www.cpsc.gov/s3fs-public/atv annual\%20Report\%202017 for website.pdf?qLMnEEqa. T8KSOdW0r8qGqpUC7gQbqEd [accessed 2019-02-13]

9. Denning GM, Harland KK, Jennissen CA. Age-based risk factors for pediatric ATV-related fatalities. Pediatrics 2014 Dec;134(6):1094-1102. [doi: 10.1542/peds.2014-1993] [Medline: 25422012]

10. Mazotas I, Toal M, Borrup K, Saleheen H, Hester AL, Copeland D, et al. A prospective, multi-institutional study of pediatric all-terrain vehicle crashes. J Trauma Acute Care Surg 2014 Jul;77(1):103-8; discussion 107. [doi: 10.1097/TA.0000000000000266] [Medline: 24977763]

11. US Government Accountability Office. 2010 Apr. All-Terrain Vehicles: How They Are Used, Crashes, and Sales of Adult-Sized Vehicles for Children's Use URL: http://www.gao.gov/new.items/d10418.pdf [accessed 2017-06-28]

12. Helmkamp JC, Aitken ME, Lawrence BA. ATV and bicycle deaths and associated costs in the United States, $2000-2005$. Public Health Rep 2009;124(3):409-418 [FREE Full text] [doi: 10.1177/003335490912400310] [Medline: 19445417] 
13. Rodgers GB, Adler P. Risk factors for all-terrain vehicle injuries: a national case-control study. Am J Epidemiol 2001 Jul 1;153(11):1112-1118. [doi: 10.1093/aje/153.11.1112] [Medline: 11390331]

14. Denning G, Jennissen C, Harland K, Ellis D, Buresh C. All-terrain vehicles (ATVs) on the road: a serious traffic safety and public health concern. Traffic Inj Prev 2013;14(1):78-85. [doi: 10.1080/15389588.2012.675110] [Medline: 23259522]

15. Denning GM, Harland KK, Ellis DG, Jennissen CA. More fatal all-terrain vehicle crashes occur on the roadway than off: increased risk-taking characterises roadway fatalities. Inj Prev 2013 Aug;19(4):250-256 [FREE Full text] [doi: 10.1136/injuryprev-2012-040548] [Medline: 23257569]

16. Insurance Institute for Highway Safety (IIHS). 2019 Dec. Fatality Facts 2018: Motorcycles and ATVs URL: https://www. iihs.org/iihs/topics/t/motorcycles/fatalityfacts/motorcycles/2017\#ATVs [accessed 2019-03-10]

17. Weintraub R. Consumer Federation of America. 2014 Mar. ATVs on Roadways: A Safety Crisis URL: https://consumerfed. org/pdfs/ATVs-on-roadways-03-2014.pdf [accessed 2019-03-17]

18. Consumer Federation of America. 2018. Coalition Letters URL: https://consumerfed.org/off-highway-vehicle-safety/ coalition-letters/ [accessed 2019-03-17]

19. Helmkamp J. CDC Blogs. 2012 Oct 24. All-Terrain Vehicles and Work URL: https://blogs.cdc.gov/niosh-science-blog/ 2012/10/24/atv/ [accessed 2019-09-14]

20. Weichelt B, Bendixsen C. A review of 2016-2017 agricultural youth injuries involving skid steers and a call for intervention and translational research. J Agromedicine 2018;23(4):374-380. [doi: 10.1080/1059924X.2018.1501455] [Medline: $\underline{30230430]}$

21. Specialty Vehicle Institute of America. URL: http://www.svia.org/\#/ [accessed 2019-02-17]

22. Occupational Safety and Health Act. 2015. Agricultural Safety Fact Sheet: All-Terrain Vehicle Hazards During Farm Work URL: https://www.osha.gov/Publications/OSHA3758.pdf [accessed 2019-02-17]

23. Jennissen C, Schaefer K, Denning G, Hendren S, Leonard S. Exposure, Crashes, and Deaths Related to the Use of All-Terrain Vehicles for Spraying. In: Proceedings of the International Society for Agricultural Safety and Health Conference. 2018 Presented at: ISASH'18; June 24-28, 2018; Halifax, Nova Scotia, Canada URL: https://www.cdc.gov/niosh/noirs/2018/ ConcurrentSessionB.html

24. Richardson RE, McMurry TL, Gepner B, Kerrigan JR. Field data analysis of recreational off-highway vehicle crashes. Traffic Inj Prev 2018;19(6):623-628. [doi: 10.1080/15389588.2018.1470326] [Medline: 30260233]

25. Nabaweesi R, Robbins JM, Goudie A, Onukwube JI, Bowman SM, Aitken ME. A cross-sectional study of emergency department visits by children after all-terrain vehicle crashes, motor vehicle crashes, and sports activities. Pediatr Emerg Care 2018 Jul;34(7):479-483. [doi: 10.1097/PEC.0000000000000776] [Medline: 27383406]

26. Karkenny AJ, Burton DA, Maguire KJ, Hanstein R, Otsuka NY. Do professional society advocacy campaigns have an impact on pediatric orthopaedic injuries? J Pediatr Orthop 2018 Mar;38(3):e122-e127. [doi: 10.1097/BPO.0000000000001133] [Medline: 29324526]

27. Testerman GM, Prior DC, Wells TD, Rollins SE, Oesch SL. Helmets matter: Kentucky all-terrain vehicle crashes seen at a Tennessee trauma center. Am Surg 2018 Mar 1;84(2):289-293. [doi: 10.14423/SMJ.0000000000000748] [Medline: 29580360]

28. Nolan HR, Ashley DW, Stokes NA, Christie DB. Increasing incidence of All-Terrain Vehicle trauma admissions in the pediatric and adult populations: An evaluation of injury types and severity. Int J Orthop Trauma Nurs 2018 Mar;28:33-36. [doi: 10.1016/j.ijotn.2017.10.001] [Medline: 29233484]

29. Flaherty MR, Raybould T, Kelleher CM, Seethala R, Lee J, Kaafarani HM, et al. Age legislation and off-road vehicle injuries in children. Pediatrics 2017 Oct;140(4) [FREE Full text] [doi: 10.1542/peds.2017-1164] [Medline: 28893850]

30. Benham EC, Ross SW, Mavilia M, Fischer PE, Christmas AB, Sing RF. Injuries from all-terrain vehicles: an opportunity for injury prevention. Am J Surg 2017 Aug;214(2):211-216. [doi: 10.1016/j.amjsurg.2016.11.017] [Medline: 27914583]

31. Lombardo DJ, Jelsema T, Gambone A, Weisman M, Petersen-Fitts G, Whaley JD, et al. Extremity fractures associated with ATVs and dirt bikes: a 10-year national epidemiologic study. Musculoskelet Surg 2017 Aug;101(2):145-151. [doi: 10.1007/s12306-016-0445-9] [Medline: 28097520]

32. Garay M, Hess J, Armstrong D, Hennrikus W. Pediatric ATV injuries in a statewide sample: 2004 to 2014 . Pediatrics 2017 Aug;140(2) [FREE Full text] [doi: 10.1542/peds.2017-0945] [Medline: 28771414]

33. Qin ES, Jennissen CA, Wadman CA, Denning GM. Using geospatial mapping to determine the impact of all-terrain vehicle crashes on both rural and urban communities. West J Emerg Med 2017 Aug;18(5):913-922 [FREE Full text] [doi: 10.5811/westjem.2017.6.34404] [Medline: 28874944]

34. Gorucu S, Murphy D, Kassab C. Risk factors for roadway single- and multi-vehicle all-terrain vehicle crashes in Pennsylvania: 2010-2013. Work 2017;57(4):555-562. [doi: 10.3233/WOR-172584] [Medline: 28777766]

35. Linnaus ME, Ragar RL, Garvey EM, Fraser JD. Injuries and outcomes associated with recreational vehicle accidents in pediatric trauma. J Pediatr Surg 2017 Mar;52(2):327-333. [doi: 10.1016/j.jpedsurg.2016.09.003] [Medline: 27670961]

36. Bethea A, Samanta D, Willis JA, Lucente FC, Chumbe JT. Substance exposure and helmet use in all-terrain vehicle accidents: nine years of experience at a level 1 trauma center. J Safety Res 2016 Dec;59:61-67 [FREE Full text] [doi: 10.1016/j.jsr.2016.09.006] [Medline: 27847000] 
37. Lagerstrom E, Magzamen S, Stallones L, Gilkey D, Rosecrance J. Understanding risk factor patterns in ATV fatalities: a recursive partitioning approach. J Safety Res 2016 Dec;59:23-31 [FREE Full text] [doi: 10.1016/j.jsr.2016.10.004] [Medline: 27846996]

38. Sciarretta JD, Harris T, Gibson S, Wentzel JL, Davis J, Pepe A. Pediatric four-wheel type vehicle injuries: outcomes and injury patterns. Am Surg 2016 Dec 1;82(11):296-297. [Medline: 28206914]

39. Williams AF, Oesch SL, McCartt AT, Teoh ER, Sims LB. On-road all-terrain vehicle (ATV) fatalities in the United States. J Safety Res 2014 Oct;50:117-123. [doi: 10.1016/j.jsr.2014.05.001] [Medline: 25142368]

40. Denning GM, Jennissen CA. What you may not know about all-terrain vehicle-related deaths and injuries. Ann Emerg Med 2016 Sep;68(3):396-397. [doi: 10.1016/j.annemergmed.2016.04.032] [Medline: 27568430]

41. Weichelt B, Gorucu S. Supplemental surveillance: a review of 2015 and 2016 agricultural injury data from news reports on AgInjuryNews.org. Inj Prev 2019 Jun;25(3):228-235. [doi: 10.1136/injuryprev-2017-042671] [Medline: 29386372]

42. Occupational Safety and Health Administration. All About OSHA URL: https://www.osha.gov/Publications/all about OSHA. pdf [accessed 2019-04-28]

43. Weichelt B, Salzwedel M, Heiberger S, Lee BC. Establishing a publicly available national database of US news articles reporting agriculture-related injuries and fatalities. Am J Ind Med 2018 May 22 [Online ahead of print]. [doi: 10.1002/ajim.22860] [Medline: 29790197]

44. Murphy D, Gorucu S, Weichelt B, Scott E, Purschwitz M. Using multiple coding schemes for classification and coding of agricultural injury. Am J Ind Med 2019 Feb;62(2):87-98. [doi: 10.1002/ajim.22932] [Medline: 30561026]

45. Centers for Disease Control and Prevention (CDC). 2019. Occupational Injury and Illness Classification System URL: https://wwwn.cdc.gov/wisards/oiics/Trees/MultiTree.aspx?Year=2012 [accessed 2019-03-10]

46. Weichelt B, Heimonen T, Gorucu S, Redmond E, Vechinski J, Pflughoeft K, et al. Redesigning a sentinel surveillance system for collecting and disseminating near real-time agricultural injury reports: system usability study. JMIR Form Res 2019 Aug 2;3(3):e13621 [FREE Full text] [doi: 10.2196/13621] [Medline: 31376278]

47. Marlenga B, Berg RL, Gallagher SS. News reports and their role in child agricultural injury prevention. J Agromedicine 2017;22(2):71-77. [doi: 10.1080/1059924X.2017.1282909] [Medline: 28107106]

48. New-Aaron M, Semin J, Duysen EG, Madsen M, Musil K, Rautiainen RH. Comparison of agricultural injuries reported in the media and census of fatal occupational injuries. J Agromedicine 2019 Jul;24(3):279-287. [doi:

10.1080/1059924X.2019.1593276] [Medline: 30890032]

49. United States Consumer Product Safety Commission. Make a FOIA Request URL: https://www.cpsc.gov/Newsroom/FOIA/ Make-a-FOIA-Request/ [accessed 2020-04-01]

50. US Consumer Product Safety Commission. 2019 Jan. NEISS Coding Manual URL: https://www.cpsc.gov/s3fs-public/ 2019 NEISS Coding Manual.pdf?kF045AF8hSkt vPuRHjyIbiet.BzcT v [accessed 2019-02-19]

51. Topping J. US Consumer Product Safety Commission. 2017 Jan. 2015 Annual Report of ATV-Related Deaths and Injuries URL: https://cpsc.gov/s3fs-public/atv_annualReport2015.pdf [accessed 2019-02-13]

52. National Highway Traffic Safety Administration. Fatality Analysis Reporting System (FARS) Encyclopedia. 2019. URL: https://www-fars.nhtsa.dot.gov/Main/index.aspx [accessed 2019-02-10]

53. National Highway Traffic Safety Administration. CrashStats - NHTSA - DOT. 2010 Apr. Report to Congress NHTSA's Crash Data Collection Programs URL: https://crashstats.nhtsa.dot.gov/Api/Public/ViewPublication/811337 [accessed 2019-02-10]

54. Byler C, Kesy L, Richardson S, Pratt SG, Rodríguez-Acosta RL. Work-related fatal motor vehicle traffic crashes: matching of 2010 data from the Census of Fatal Occupational Injuries and the Fatality Analysis Reporting System. Accid Anal Prev 2016 Jul;92:97-106. [doi: 10.1016/j.aap.2016.02.004] [Medline: 27054483]

55. National Highway Traffic Safety Administration. CrashStats - NHTSA - DOT. 2018 Oct. 2017 FARS/CRSS Coding and Validation Manual URL: https://crashstats.nhtsa.dot.gov/Api/Public/ViewPublication/812559 [accessed 2019-03-25]

56. National Highway Traffic Safety Administration. CrashStats - NHTSA - DOT. 2018. Fatality Analysis Report System (FARS). Analytical User's Manual 1975-2017 URL: https://crashstats.nhtsa.dot.gov/Api/Public/ViewPublication/812602 [accessed 2019-02-10]

57. The National Center for Fatality Review and Prevention. 2019. URL: https://www.ncfrp.org/ [accessed 2019-02-10]

58. The National Center for Fatality Review and Prevention. Data Dissemination URL: https://www.ncfrp.org/resources/ data-dissemination/ [accessed 2020-04-02]

59. Rostas JW, Donnellan KA, Gonzalez RP, Brevard SB, Ahmed N, Rogers EA, et al. Helmet use is associated with a decrease in intracranial hemorrhage following all-terrain vehicle crashes. J Trauma Acute Care Surg 2014 Jan;76(1):201-204. [doi: 10.1097/TA.0b013e3182a994ff] [Medline: 24368380]

60. Winfield RD, Mozingo DW, Armstrong JH, Hollenbeck JI, Richards WT, Martin LC, et al. All-terrain vehicle safety in Florida: is legislation really the answer? Am Surg 2010 Mar;76(2):149-153. [Medline: 20336890]

61. Miller M, Davidov D, Tillotson R, Whiteman C, Marshall T, Lander O. Injury prevention and recreational all-terrain vehicle use: the impact of helmet use in West Virginia. W V Med J 2012;108(3):96-101. [Medline: 22792664]

62. Pelletier J, McKee J, Ozegovic D, Widder S. Retrospective review of all-terrain vehicle accidents in Alberta. Can J Surg 2012 Aug;55(4):249-253 [FREE Full text] [doi: 10.1503/cjs.036210] [Medline: 22617540] 
63. Merrigan TL, Wall PL, Smith HL, Janus TJ, Sidwell RA. The burden of unhelmeted and uninsured ATV drivers and passengers. Traffic Inj Prev 2011 Jul;12(3):251-255. [doi: 10.1080/15389588.2011.561455] [Medline: 21660891]

64. Rattan R, Joseph DK, Dente CJ, Klein EN, Kimbrough MK, Nguyen J, et al. Prevention of all-terrain vehicle injuries: a systematic review from The Eastern Association for the Surgery of Trauma. J Trauma Acute Care Surg 2018 Jun;84(6):1017-1026 [FREE Full text] [doi: 10.1097/TA.0000000000001828] [Medline: 29389840]

65. Qin ES, Denning GM, Jennissen CA. Enforcement of off-road vehicle laws in Iowa. Safety 2019 Apr 23;5(2):22 [FREE Full text] [doi: 10.3390/safety5020022]

\author{
Abbreviations \\ AgFF: agriculture, fishing, and forestry \\ ATV: all-terrain vehicle \\ BAC: blood alcohol level \\ BLS: Bureau of Labor Statistics \\ CDR: child death review \\ CFA: Consumer Federation of America \\ CPSC: Consumer Product Safety Commission \\ CRS: Case Reporting System \\ DOT: department of transportation \\ ED: emergency department \\ FAIC: farm and agricultural injury classification \\ FARS: Fatality Analysis Reporting System \\ NCFRP: National Center for Fatality Review and Prevention \\ NEISS: National Electronic Injury Surveillance System \\ NHTSA: National Highway Traffic Safety Administration \\ NIOSH: National Institute for Occupational Safety and Health \\ OIICS: Occupational Injury and Illness Classification System \\ ORV: off-road vehicle \\ OSHA: Occupational Safety and Health Administration \\ ROPS: rollover protective structures \\ ROV: recreational off-highway vehicle \\ S $\times$ S: side-by-side \\ UTV: utility task/terrain vehicle \\ VIN: vehicle identification number
}

Edited by T Sanchez; submitted 12.07.19; peer-reviewed by F Khorsandi, D Jepsen, I Idris, K Goniewicz; comments to author 23.08.19;
revised version received 17.01.20; accepted 15.02.20; published 29.05.20
Please cite as:
Weichelt B, Gorucu S, Jennissen C, Denning G, Oesch S
Assessing the Emergent Public Health Concern of All-Terrain Vehicle Injuries in Rural and Agricultural Environments: Initial Review
of Available National Datasets in the United States
JMIR Public Health Surveill 2020;6(2):e15477
URL: http://publichealth.jmir.org/2020/2/e15477/
doi: $\underline{10.2196 / 15477}$
PMID: $\underline{32469319}$

CBryan Weichelt, Serap Gorucu, Charles Jennissen, Gerene Denning, Stephen Oesch. Originally published in JMIR Public Health and Surveillance (http://publichealth.jmir.org), 29.05.2020. This is an open-access article distributed under the terms of the Creative Commons Attribution License (https://creativecommons.org/licenses/by/4.0/), which permits unrestricted use, distribution, and reproduction in any medium, provided the original work, first published in JMIR Public Health and Surveillance, is properly cited. The complete bibliographic information, a link to the original publication on http://publichealth.jmir.org, as well as this copyright and license information must be included. 